\title{
Peran Rotasi Kerja Terhadap Kinerja Pegawai
}

\author{
Dewi Untari ${ }^{*}$, Wendy Muliadi ${ }^{2}$ \\ ${ }^{1}$ Politeknik Kridatama \\ Jl. Terusan Borobudur, No. 1-4, Bandung, Indonesia \\ ${ }^{2}$ STIE Kridatama Bandung \\ Jl. Borobudur No.1-4, Cibaduyut Kidul, Bandung, Indonesia \\ *email: dew11untari@gmai.com
}

\begin{tabular}{|c|c|}
\hline Artikel Info & ABSTRAK \\
\hline $\begin{array}{l}\text { Received: } \\
29 \text { Agustus } 2018 \\
\quad \text { Revised: } \\
1 \text { September } 2018 \\
\quad \text { Accepted: } \\
5 \text { Oktober } 2018\end{array}$ & $\begin{array}{l}\text { Pengukuran kinerja pegawai sektor publik yang berorentasi pada hasil (outcome) bukan } \\
\text { hanya sekedar pengukuran (input) dan (output) saja, melainkan suatu proses penilaian } \\
\text { kemajuan pekerjaan terhadap pecapaian tujuan dan sasaran yang telah ditentukan, } \\
\text { sehingga penelitian ini bertujuan untuk mengetahui dampak rotasi kerja terhadap } \\
\text { kinerja pegawa. Penelitian ini adalah penelitian deskriptif menggunakan data-data } \\
\text { statistic yang bersumber dari data primer. Metode yang digunakan pada penelitian ini }\end{array}$ \\
\hline & $\begin{array}{l}\text { adalah statistik deskriptif. Sampel dalam penelitian ini sebanyak } 64 \text { responden. } \\
\text { Penelitian ini dilakukan di Simed Prakarsa Indonesia. Hasil penelitian menunjukan } \\
\text { bahwa sistem rotasi kerja telah dilaksanakan dengan baik untuk tingkat kinerja } \\
\text { organisasi juga pada kategori baik, dengan tingkat pencapaian sebesar tingkat keeratan } \\
\text { hubungan antara rotasi kerja dengan kinerja. }\end{array}$ \\
\hline
\end{tabular}

Kata Kunci: Rotasi kerja, Kinerja pegawai

\section{The Role of Work Rotation on Employee Performance}

\begin{abstract}
Performance measurement of public sector employees that are oriented to results (output) is not just assessment (input) and (output) only, the process of discussing progress related to the achievement of predetermined goals and objectives so that this study aims to improve employment relations of employee performance. This study is a descriptive study using data statistics derived from primary data. The method used in this study is descriptive statistics. The sample in this study amounted to 64 respondents. This research was conducted at Simed Prakarsa Indonesia. The results of the study show that the work rotation system that has been done well for the level of organizational performance is also in the good category, with a level of achievement at the level of closeness.
\end{abstract}

Keywords: Work rotation, Employee performance

Cara Sitasi :

Muliadi, W., Untari, D. (2018). Peran Rotasi Kerja Terhadap Kinerja Pegawai. Jurnal Ilmiah Manajemen dan Bisnis, 19(2), 110-116. https://doi.org/ 10.30596/jimb.v19i2.2158. 


\section{PENDAHULUAN}

Pengembangan Sumber Daya Manusia DM merupakan cara organisasi agar dapat mempertahankan eksistensi kerja semua komponen organisasi. Sebuah pengembangan yang matang agar SDM yang dimiliki sebuah organisasi terpakai sesuai kebutuhan. Pengembangan SDM dapat dilakukan dengan berbagai cara, salah satunya adalah dengan melalui rotasi kerja. Dengan adanya rotasi kerja karyawan tidak merasa jenuh, bosan sehingga karyawan dapat menghasilkan keluaran (output) yang tinggi.

Sumber Daya Manusia merupakan kekuatan daya pikir dan karya manusia yang masih tersimpan didalam dirinya yang perlu dibina dan digali serta dikembangkan untuk dimanfaatkan sebaik-baiknya bagi kesejhteraan kehidupan masyarakat. Kinerja pegawai merupakan suatu hasil yang dicapai oleh pegawai tersebut dalam pekerjaannya menurut criteria yang berlaku untuk suatu pekerjaan tertentu, berhasil tidaknya kinerja pegawai yang telah dicapai dipengaruhi oleh tingkat kinerja dari pegawai secara individu atau kelompok.

Rotasi jabatan sendiri memiliki beberapa arti, Hasibuan, (2003) mengemukakan perubahan tempat atau jabatan karyawan tetapi masih pada rangking yang sama di dalam organisasi itu, istilah-istilah yang sama dengan rotasi Jabatan adalah mutasi, pemindahan dan transfer, sedangkan Hariandja, (2005); Robbins \& Judge, (2008) berpendapat rotasi hanya proses perpindahan posisi dalam pekerjaan secara horizontal yang bertujuan untuk mengatasi kejenuhan dalam bekerja, meningkatkan pengetahuan maupun keahlian karyawan.

Menghadapi situasi yang demikian aparatur yang ada di PT Simed Prakarsa Indonesia dituntut untuk selalu meningkatkan kualitas baik kemampuan, keterampilan, kreativitas, pengetahuan, tanggung jawab, displin serta keteladanan maupun profesionalisme. Hal ini penting agar dalam menjalankan tanggung jawab dapat berjalan dengan baik sesuai dengan pelaksanaan tugas pokok dan fungsinya organisasi yaitu dalam rangka pencapaian Visi dan Misi Tujuan Organisasi. Menyadari akan tugas untuk tercapainya Visi dan Misi Tujuan Organisasi maka dilakukan upaya-upaya positif dalam rangka meningkatkan kinerja pegawai, upayaupaya tersebut dapat dilakukan dengan jalan melakukan perbaikan sistem yang harus dilakukan secara terprogram, terjadwal dan berkesinambungan agar pegawai merasa diperlakukan secara adil dan merata. Berdasarkan Kebijakan PT Simed Prakarsa Indonesia tahun 2013-2018, salah satu faktor yang memunculkan kendala internal dan menyebabkan terganggunya kinerja PT Simed Prakarsa Indonesia adalah persoalan sumber daya manusia (SDM). Para pegawai masih dianggap belum bekerja "lebih" dari target dan tujuan. Artinya, pegawai masih bekerja seadanya selama masih sesuai standar prosedur yang diharapkan. Kondisi ini bisa disebabkan karena faktor keberadaan mereka pada lembaga publik, yakni salah satunya berupa persoalan kompensasi atau gaji yang menjadi salah satu motivasi, sudah terjamin oleh negara. Pada akhirnya, inilah yang menyebabkan PT Simed Prakarsa Indonesiabelum dapat menyajikan siaran yang menarik dan diminati masyarakat. Para pegawai belum dapat bekerja dengan menunjukkan kualitas yang diharapkan. Untuk bagian fungsional loperator PT Simed Prakarsa Indonesia tidak terkena Rotasi Kerja/ Tour Of Duty, terkecuali yang personal yang bersangkutan ada masalah internal yang memungkinkan untuk dipindah, karena fungsi professional diutamakan pada pegawai fungsional. Demikian juga bagi pegawai administrasi berlaku hal yang sama tidak terkena Rotasi Kerja, kecuali pegawai tersebut diangkat 
menjadi pejabat managerial. Untuk pejabat managerial berlaku Rotasi Kerja/Tour Of Duty dimana pada suatu tempat dan posisi seorang pejabat managerial tidak boleh menjabat lebih dari 4 tahun.

Alasan lain dilakukannya rotasi pekerjaan adalah bahwa tugas atau pekerjaan bersifat monoton yang dilaksanakan terus menerus dapat mengakibatkan kebosanan dan penurunan hasil kerja dari pegawai (Tumipa \& Rumokoy, 2018). Adanya rotasi pekerjaan diharapkan dapat menstimulasi karyawan untuk mencapai kinerja yang lebih baik karena terdapat proses penambahan pengetahuan dan kemampuan pegawai, mengurangi kejenuhan kerja dari pegawai, membantu proses penempatan pegawai secara tepat, serta memberi tantangan lebih besar bagi pegawai untuk mencapai prestasi atau kinerja yang lebih baik (Rahman \& Solikhah, 2016).

Rotasi pekerjaan salah satu pendekatan yang penting dari desain pekerjaan serta kebijakan pengembangan sumber daya manusia yang memiliki potensi untuk meningkatkan kinerja karyawan melalui kepuasan kerja (Saravani \& Abbasi, 2013), rotasi pekerjaan diharapkan dapat mengurangi kebosanan kerja, mempersiapkan manajemen kerja yang lebih baik, meningkatkan komunikasi sosial, dan meningkatkan kemampuan keterampilan dalam bekerja, dan yang paling utama diharapkan dari rotasi pekerjaan adalah dapat meningkatkan kinerja karyawan (Jamil, 2016). Rotasi pekerjaan secara tidak langsung memberikan manfaat bagi organisasi karena karyawan yang mempunyai banyak keterampilan memberi manajemen lebih banyak dalam merencanakan pekerjaan, menyesuaikan diri terhadap perubahan dan mengisi lowongan-lowongan (Salih \& Al.Ibed, 2017), selain itu rotasi kerja juga akan bermanfaat untuk pengembangan sumber daya manusia rotasi kerja diyakini dapat memberikan banyak manfaat lain bagi organisasi, rotasi dapat mencegah timbulnya kebosanan dan dapat juga mengurangi labour turnover (absennya pekerja) karyawan. Manfaat tidak langsung, rotasi kerja bagi organisasi adalah ketika karyawan yang memiliki katrampilan lebih luas pada berbagai bidang.

Merotasikan karyawan pada posisi yang tepat pada prinsipnya untuk meningkatkan semangat dan produktivitas kerja, kemudian untuk menciptakan atau meningkatkan efisiensi dan efektivitas kerja dalam suatu organisasi, sebagaimana yang dikemukakan oleh Tumipa \& Rumokoy, (2018).

Hasibuan, (2003) membagi dasar Rotasi Jabatan menjadi tiga landasan pelaksanaan, antara lain: Merit System, yaitu perpindahan jabatan yang didasarkan atas landasan yang bersifat ilmiah, objektif dan hasil prestasi kerjanya. Sistem ini termasuk dasar Rotasi Jabatan yang baik karena dapat meningkatkan semangat dan disiplin karyawan sehingga produktivitasnya meningkat. Seniority System, yaitu perpindahan jabatan yang didasarkan atas landasan masa kerja, usia dan pengalaman kerja dari jabatan yang bersangakutan. Sistem ini tidak objektif karena kecakapan orang yang dipindahkan didasarkan pada senioritas dan belum tentu mampu memangku jabatan yang baru. Spoil System, yaitu perpindahan jabatan yang didasarkan atas landasan kekeluargaan, sistem ini kurang baik karena didasarkan atas pertimbangan suka atau tidak suka.

Hasil atau tingkat keberhasilan seseorang secara keseluruan selama priode tertentu didalam melaksanakan tugas dihadapkan dengan berbagai kemungkinan seperti standar hasil kerja target atau sasaran atau kreteria yang telah ditentukan terlebih dahulu dan telah disepakati bersama untuk mewujudkan sasaran, tujuan, visi,misi 
Published Oktober 2018

JURNAL ILMIAH MANAJEMEN DAN BISNIS

ISSN 1693-7619 (print) | ISSN 2580-4170 (online), http://jurnal.umsu.ac.id/index.php/mbisnis

organisasi yang tertuang dalam strategic planning suatu organisasi. Tujuan penilaian kinerja penilaian kinerja adalah penetuan secara periodic efektivitas operasi suatu organisasi, bagian organisasi dan personalnya, berdasarkan sasaran, standar, dan kriteria yang telah ditetapkan sebelumnya oleh karena organisasi pada dasarnya dioperasikan oleh sumber daya manusia (Brougham \& Haar, 2017), faktor lain yang mempengaruhi kinerja pegawai adalah rotasi pekerjaan. Pekerjaan yang sifatnya rutin itu-itu saja (monoton) akan menimbulkan kebosanan atau kejenuhan yang akan mengakibatkan turunya semangat dan gairah kerja. Oleh karena itu dalam bentuk pengembangan dan pengoptimalan kinerja pegawai maka kebijakan rotasipekerjaan diterapkan. Rotasi kerja adalah pendekatan yang penting dari desain pekerjaan serta kebijakan pengembangan sumber daya manusia yang memiliki potensi untuk meningkatkan kinerja pegawai melalui kepuasan kerja saravani dan Abbasi (Saravani \& Abbasi, 2013), ini rotasi pekerjaan diharapkan dapat mengurangi monoton atau kebosanan kerja. Mempersiapkan manajemen kerja yang lebih baik, meningkatkan komunikasi sosial, dan meningkatkan kemampuan keterampilan dalam bekerja. Tujuan yang paling utama daiharapkan dari rotasi pekerjaan adalah dapat meningkatkan kinerja pegawai.

\section{METODE}

Penelitian ini menggunakan pendekatan statistic deskriptif dengan mengunakan berdasarkan fakta-fakta yang tampak atau sebagaimana adanya. Usaha mendeskriptifkan fakta-fakta itu pada tahap permulaan tertuju pada usaha mengemukakan gejala-gejala secara lengkap dalam aspek yang diselidiki, agar jelas keadaan atau kondisinya. Pendekatan kuantitatif lebih menekankan pada data berupa angka atau jumlah dengan berbagai klasifikasi, antara lain berbentuk frekuensi, nilai rata-rata, persentase, dengan menunjukan perbedaan, perbandingan, tingkatan dan yang diolah secara matematis dengan mungunakan rumus statistik. Jenis data yang dipergunakan dalam penelitian ini adalah data primer, teknik pengmpulan data dengan cara penyebaran kuesioner atau angket, yang berisi pernyataan yang sifatnya tertutup (telah disediakan jawabannya) kepada responden penelitian, yaitu karyawan PT Simed Prakarsa Indonesia yang berjumlah 64 orang.

\section{HASIL PENELITIAN DAN PEMBAHASAN}

Permasalahan ini adalah "Terdapat Pengaruh Rotasi Kerja Terhadap Kinerja Pegawai Pada PT Simed Prakarsa Indonesia, maka pengujian untuk mengetahui hubungan antara variabel $\mathrm{X}$ dan $\mathrm{Y}$ dicari dengan mungunakan rumus korelasi rank Spearman.

Tabel 2. Hasil Analisis Statistik Variabel

Rotasi Kerja

\begin{tabular}{|c|l|c|c|c|c|}
\hline No & \multicolumn{1}{|c|}{ Dimensi } & Skor & $\begin{array}{l}\text { Skor } \\
\text { ideal }\end{array}$ & $\%$ & Kategori \\
\hline 1 & $\begin{array}{l}\text { Prestasi } \\
\text { Kerja }\end{array}$ & 1010 & 1280 & 78,90 & Baik \\
\hline 2 & $\begin{array}{l}\text { Pengalaman } \\
\text { kerja }\end{array}$ & 756 & 960 & 78,75 & Baik \\
\hline 3 & $\begin{array}{l}\text { Tingkat } \\
\text { kebutuhan } \\
\text { pegawai }\end{array}$ & 709 & 960 & 73,85 & Baik \\
\hline \multicolumn{2}{|l|}{ Jumlah } & 2475 & 3200 & 77.34 & Baik \\
\hline
\end{tabular}

Tabel 2, rata-rata tingkat pencapaian persetujuan responden untuk variabel Rotasi Kerja mencapai 77.34, hasil ini mencerminkan bahwa kondisi Rotasi Kerja dalam kondisi baik. 
Tabel 3. Hasil Analisis Data Variabel Kinerja Pegawai

\begin{tabular}{|c|l|c|c|c|c|}
\hline No & Dimensi & Skor & $\begin{array}{c}\text { Skor } \\
\text { ideal }\end{array}$ & $\%$ & Kategori \\
\hline 1 & Input & 976 & 1280 & 66,56 & $\begin{array}{c}\text { Cukup } \\
\text { Baik }\end{array}$ \\
\hline 2 & Output & 1193 & 1600 & 74,56 & Baik \\
\hline 3 & Outcome & 493 & 640 & 77,03 & Baik \\
\hline & Jumlah & 2662 & 3520 & 75,62 & Baik \\
\hline
\end{tabular}

Tabel 3, rata-rata tingkat pencapaian persetujuan responden untuk variabel rotasi kerja mencapai 77.34, hasil ini mencerminkan bahwa kondisi Kinerja Pegawai dalam kondisi baik.

\section{Pembahasan}

Rotasi berdasarkan tingkat kebutuhan pegawai dalam organisasi, dimana pegawai hendaknya mengetahui dasar perpindahan posisi dalam bekerja, karena jangan sampai rotasi jabatan akan membuat pegawai tidak nyaman dan akan menimbulkan masalahmasalah dalam bekerja. Rotasi jabatan merupakan suatu mutasi personal yang dilakukan secara horizontal tanpa menimbulkan perubahan dalam hal gaji ataupun pangkat atau golongan dengan tujuan untuk menambah pengetahuan dan pengalaman serta untuk menghindari kejenuhan (Shinta, et al., 2016), alasan lain dilakukannya rotasi pekerjaan adalah bahwa tugas atau pekerjaan bersifat monoton yang dilaksanakan terus menerus dapat mengakibatkan kebosanan dan penurunan hasil kerja dari pegawai (Saputra, et al., 2015; Akbari \& Maniei, 2017), dengan rotasi pekerjaan diharapkan dapat menstimulasi karyawan untuk mencapai kinerja yang lebih baik karena terdapat proses penambahan pengetahuan dan kemampuan pegawai, mengurangi kejenuhan kerja dari pegawai, membantu proses penempatan pegawai secara tepat, serta memberi tantangan lebih besar bagi pegawai untuk mencapai prestasi atau kinerja yang lebih baik (Rahman \&
Solikhah, 2016; (Santoso, 2009; Saputra et al., 2015). Rotasi kerja merupakan suatu perubahan posisi tempat pekerjaan yang dilakukan pimpinan puncak organisasi kepada seseorangyaitu pegawai baik secara horizontal maupun vertikal didalam suatu instasi atau perusahaan (Kampkötter, et al., 2016; Shinta et al., 2016), maksud dari pendapat pimpinan tersebut adalah suatu perusahaan akan dapat mendapat banyak keuntungandari pelaksanaan rotasi pekerjaan yaitu pegawai akan menjadi lebih berkompeten dalam beberapa pekerjaan (Tumipa \& Rumokoy, 2018; Rahmawati \& Kurnia, 2017), menambah berbagai pengetahuan dalam berbagai macam pekerjaan dan membuat pegawai lebih berguna bagi instansi atau perusahaan tersebut (Dhanraj \& Parumasur, 2014). Rotasi kerja mempengaruhi kinerja pegawai sebesar $50.04 \%$ dan sisanya sebesar $49.96 \%$ dipengaruhi variabel lain seperti kompetensi pegawai, tingkat pendidikan, gaya kepemimpinan, visi dan misi kerja pengaruh rotasi kerja berkaitan erat dengan aktivitas pegawai, rotasi kerja akan efektif bila rotasi tersebut menyatu dengan infrastruktur dan merupakan bagian penting bagi pegawai perusahaan, sehinga dengan diterapkan rotasi kerja pada pegawai akhirnya dapat meningkatkan kinerja pegawai .

Pekerjaan yang sifatnya rutin itu-itu saja (monoton) akan menimbulkan kebosanan atau kejenuhan yang akan mengakibatkan turunya semangat dan gairah kerja Jamil, (2016); (Dhanraj \& Parumasur, (2014). Oleh karena itu dalam bentuk pengembangan dan pengoptimalan kinerja pegawai maka kebijakan rotasipekerjaan diterapkan. Rotasi kerja adalah pendekatan yang penting dari desain pekerjaan serta kebijakan pengembangan sumber daya manusia yang memiliki potensi untuk meningkatkan kinerja pegawai melalui kepuasan kerja (Saravani \& Abbasi, 2013; Rahmawati \& Kurnia, 2017). Kinerja 


\section{Published Oktober 2018 \\ JURNAL ILMIAH MANAJEMEN DAN BISNIS \\ ISSN 1693-7619 (print) | ISSN 2580-4170 (online), http://jurnal.umsu.ac.id/index.php/mbisnis}

Pegawai di PT Simed Prakarsa Indonesia berdasarkan analisis deskriptif atas frekuesi jawaban responden menunjukkan tingkat kinerja pegawai rata-rata sebesar $75,62 \%$ ini menunjukkan bahwa tingkat kinerja pegawai dalam kondisi baik,

Koefisien korelasi rank Spearman sebesar (+) 0,504 hal ini menunjukan bahwa pengaruh rotasi kerja mempengaruhi kinerja pegawai sebesar 50,04\%dan sisanya sebesar 49,96\% dipengaruhi variabel lain seperti kompetensi pegawai, tingkat pendidikan, gaya kepemimpinan, visi dan misi kerja pengaruh rotasi kerja berkaitan erat dengan aktivitas pegawai, rotasi kerja akan efektif bila rotasi tersebut menyatu dengan infrastruktur dan merupakan bagian penting bagi pegawai perusahaan rivat maupun publik. Sehingga dengan diterapkan rotasi kerja pada pegawai akhirnya dapat meningkatkan kinerja pegawai.

\section{SIMPULAN}

Rotasi Kerja pada PT Simed Prakarsa Indonesia dalam kondisi baik sedangkan kinerja Pegawai di PT Simed Prakarsa Indonesia menunjukkan tingkat kinerja pegawai dalam kondisi baik, rotasi kerja berkaitan erat dengan aktivitas pegawai, rotasi kerja akan efektif bila rotasi menyatu dengan infrastruktur dan merupakan bagian penting bagi pegawai perusahaan, sehingga dengan diterapkan rotasi kerja pada pegawai akhirnya dapat meningkatkan kinerja pegawai. Dengan demikian secara implikasi dari hasil penelitian ini rotasi kerja dilakukan secara berkala (mingguan, bulanan dan tahunan) supaya tidak terjadi kebosanan atau kejenuhan serta menurunnya semangat kerja dan gairah kerja. Kompetensi pegawai melalui orentasi harus sering dilaksanakan pada PT Simed Prakarsa Indonesia. Program rotasi pegawai harus didukung oleh sumber daya manusia (SDM) yang berpengaruh terhadap produktivitas pegawai baik segi keterampilan, pengetahuan, keahlian dan sikap mental.

\section{REFERENSI}

Akbari, A., \& Maniei, R. (2017). The Effect of Job Rotation on employee performance. Research Journal of Management Reviews, 3(1), 21-26.

Brougham, D., \& Haar, J. (2017). Employee assessment of their technological redundancy. Labour \& Industry: A Journal of the Social and Economic Relations of Work, 27(3), 213-231. https://doi.org/10.1080/10301763.2017 .1369718

Dhanraj, D., \& Parumasur, S. B. (2014). Perceptions of The Impact of Job Rotation on Employees, Productivity, The Organization and on Job Security. Corporate Ownership \& Control, 11(4), 682-691.

Hariandja, M. T. E. (2005). Manajemen Sumber Daya Manusia: Pengadaan, Pengembangan, Pengkompensasian, dan Peningkatan Produktivitas Pegawai. Jakarta: Grasindo.

Hasibuan, M. S. . (2003). Manajemen Personalia. Jakarta: Bumi Aksara.

Jamil, M. (2016). Rotasi Pekerjaan dan Kinerja Karyawan: Peran Kepuasan Kerja dan Variasi Keterampilan Kerja Sebagai Variabel Intervening. Jurnal Ekonomi Manajemen Dan Sekretari, 1(2), $96=117$.

Kampkötter, P., Harbring, C., \& Sliwka, D. (2016). Job rotation and employee performance - evidence from a longitudinal study in the financial services industry. The International Journal of Human Resource Management, 29(10), 1709-1735. https://doi.org/10.1080/09585192.2016 .1209227

Rahman, T., \& Solikhah, S. (2016). Analisis Pengaruh Rotasi Kerja, Motivasi Kerja dan Kepuasan Kerja terhadap Kinerja 


\section{JURNAL ILMIAH MANAJEMEN DAN BISNIS \\ ISSN 1693-7619 (print) | ISSN 2580-4170 (online), http://jurnal.umsu.ac.id/index.php/mbisnis}

Karyawan di Lembaga Keuangan Mikro Syariah. Jurnal Muqtasid, 7(2), 23-49.

Rahmawati, R., \& Kurnia, M. (2017). The Effect of Job Rotation, Compensation and Work on Employee Performance With Work Satisfaction as Intervening Varible Case Study in General Hospital (RSUD) Tidar Kota Magelang. In The 6th University Research Colloquium 2017 Universitas Muhammadiyah Magelang (pp. 377390). Magelang: Universitas Muhammadiyah Magelang.

Robbins, S. P., \& Judge, T. A. (2008). Perilaku Organisasi (Organizational Behavior) (Edisi Kedu). Jakarta: Penerbit Salemba Empat.

Salih, M. O. I., \& Al.Ibed, A. B. A. N. Y. (2017). Job Rotation \& Its Impact on employees' Performance: An Empirical Study among Employees at Red Sea University, Sudan. International Journal of Scientific Research and Management (IJSRM), 5(07), 6181-6184. https://doi.org/10.18535/ijsrm/v5i7.46

Santoso. (2009). Pengaruh Rotasi Pegawai, Kepuasan Kerja Dan Perilaku Kerja Terhadap Kinerja Pegawai Negeri Sipil Di Lingkungan Balai Pendidikan Dan Pelatihan Transportasi Darat Palembang. Jurnal Media Wahana Ekonomika, 13(4), 61-68.

Saputra, A. M. E. E., Musadieq, M. Al, \& Prasetya, A. (2015). Pengaruh On The Job Training dan Off The Job Training Terhadap Kinerja (Studi pada Karyawan PT. Bank Pembangunan Daerah Jawa Timur, Tbk Cabang Pare). Jurnal Administrasi Bisnis (JAB), 27(2), 1-10.

Saravani, S. R., \& Abbasi, B. (2013). Investigating The Influence of Job Rotation on Performance By Considering Skill Variation And Job
Satisfaction of Bank Employees. Tehnički Vjesnik, 20(3), 473-478.

Shinta, A., Nurhadi, Harry, T. A. P., \& Mahmudah, S. (2016). Kesiapan Karyawan Administrasi Yang Terkena Rotasi Kerja Pada Bagian Pemasaran. Jurnal Psikologi, 12(September), 6677.

Tumipa, V., \& Rumokoy, F. S. (2018). The Role Of Job Rotation Practices Towards Employee Performance In Kantor Pelayanan Kekayaan Negara Dan Lelang (KPKNL). Jurnal EMBA, 6(2), 898-907. 